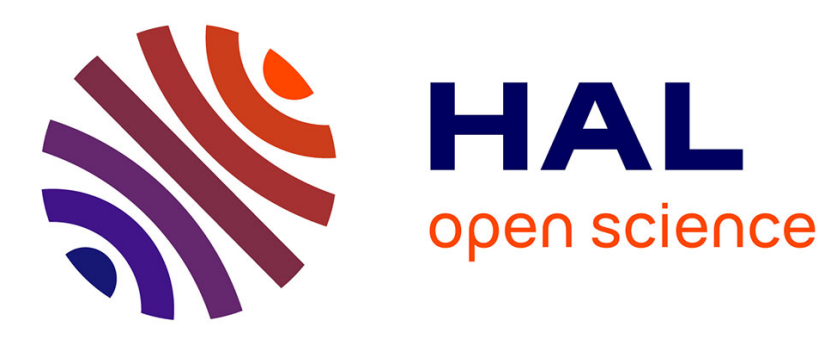

\title{
Making Sense of the Experimental Evidence on Endogenous Timing in Duopoly Markets
}

\author{
Luís Santos-Pinto
}

\section{To cite this version:}

Luís Santos-Pinto. Making Sense of the Experimental Evidence on Endogenous Timing in Duopoly Markets. Journal of Economic Behavior and Organization, 2008, 68 (3-4), pp.657. 10.1016/j.jebo.2008.06.005 . hal-00643019

\section{HAL Id: hal-00643019 https://hal.science/hal-00643019}

Submitted on 21 Nov 2011

HAL is a multi-disciplinary open access archive for the deposit and dissemination of scientific research documents, whether they are published or not. The documents may come from teaching and research institutions in France or abroad, or from public or private research centers.
L'archive ouverte pluridisciplinaire HAL, est destinée au dépôt et à la diffusion de documents scientifiques de niveau recherche, publiés ou non, émanant des établissements d'enseignement et de recherche français ou étrangers, des laboratoires publics ou privés. 


\section{Accepted Manuscript}

Title: Making Sense of the Experimental Evidence on Endogenous Timing in Duopoly Markets

Author: Luís Santos-Pinto

PII: $\quad$ S0167-2681(08)00129-7

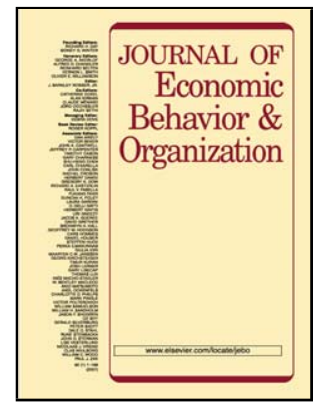

DOI: $\quad$ doi:10.1016/j.jebo.2008.06.005

Reference: $\quad$ JEBO 2226

To appear in: Journal of Economic Behavior \& Organization

Received date: 6-9-2006

Revised date: $\quad$ 17-6-2008

Accepted date: $\quad 18-6-2008$

Please cite this article as: Santos-Pinto, L., Making Sense of the Experimental Evidence on Endogenous Timing in Duopoly Markets, Journal of Economic Behavior and Organization (2007), doi:10.1016/j.jebo.2008.06.005

This is a PDF file of an unedited manuscript that has been accepted for publication. As a service to our customers we are providing this early version of the manuscript. The manuscript will undergo copyediting, typesetting, and review of the resulting proof before it is published in its final form. Please note that during the production process errors may be discovered which could affect the content, and all legal disclaimers that apply to the journal pertain. 


\title{
Making Sense of the Experimental Evidence on Endogenous Timing in Duopoly Markets ${ }^{\dagger}$
}

\author{
Luís Santos-Pinto \\ Universidade Nova de Lisboa, Departamento de Economia \\ Campus de Campolide, PT-1099-032, Lisboa, Portugal \\ Email address: lspinto@fe.unl.pt
}

June 16, 2008

\begin{abstract}
The prediction of asymmetric equilibria with Stackelberg outcomes is clearly the most frequent result in the endogenous timing literature. Several experiments have tried to validate this prediction empirically, but failed to find support for it. In contrast, these experiments find that simultaneous-move outcomes are modal and that behavior in endogenous timing games is quite heterogeneous. This paper generalizes Hamilton and Slutsky's (1990) endogenous timing games by assuming that players are averse to inequality in payoffs. I explore the theoretical implications of inequity aversion and compare them to the empirical evidence. I find that this explanation is able to organize most of the experimental evidence on endogenous timing games. However, inequity aversion is not able to explain delay in Hamilton and Slutsky's endogenous timing games.
\end{abstract}

JEL Classification Numbers: C72, D43, D63, L13.

Keywords: Endogenous Timing; Cournot; Stackelberg; Inequity Aversion.

${ }^{\dagger}$ I am thankful for comments made by an anonymous referee and by participants of the 2006 Conference of the European Association for Research in Industrial Economics (EARIE). I gratefully acknowledge financial support from an INOVA grant. 


\section{Introduction}

The theoretical literature on endogenous timing started with Saloner (1987), Hamilton and Slutsky (1990), and Robson (1990). This literature tries to identify factors that might lead to the endogenous emergence of sequential or simultaneous play in oligopolistic markets.

In Hamilton and Slutsky's action commitment game, two firms must decide a quantity to be produced in one of two periods before the market clears. If a firm commits to a quantity in the first period, it acts as the leader, but it does not know whether the other firm has chosen to commit early or not. If a firm commits to a quantity in the second period, then it observes the first period production of the rival (or its decision to wait). Hamilton and Slutsky show that this game has three SPNE: both firms committing in the first period to the simultaneous-move Cournot-Nash equilibrium quantities, while the other plays its Stackelberg leader quantity in the first period. They also show that only the Stackelberg equilibria survive elimination of weakly dominated strategies. ${ }^{1}$

Observed behavior in experiments on this canonical model of endogenous timing is at odds with the theory. For example, Huck et al. (2002) test experimentally the predictions of Hamilton and Slutsky's action commitment game. They find that (i) Stackelberg outcomes are rare, (ii) simultaneous-move Cournot outcomes are modal, (iii) simultaneous-move outcomes are often played in the second production period, and (iv) behavior is quite heterogeneous: in some cases followers punish leaders, in other cases collusive outcomes are played, and in other cases Stackelberg warfare is observed. ${ }^{2}$

The questions that the endogenous timing literature tries to address are particularly relevant in terms of new markets, where two or more firms will enter. The experimental evidence suggests that simultaneous-move play may a better predictor of behavior in markets for new goods than sequential play. ${ }^{3}$ It also suggests that there may be substantial heterogeneity in behavior in these markets. ${ }^{4}$

Why does the theory perform poorly in the experiments? One possibility is that subjects are not able iteratively to rule out dominated strategies and stop after one or two rounds of reasoning. There is substantial experimental evidence that supports this view. Even if subjects are able to eliminate dominated strategies, the two Stackelberg equilibria involve large payoff differences, and this creates a coordination problem. This implies that playing the Stackelberg

\footnotetext{
${ }^{1} \mathrm{~A}$ model where the price is chosen was considered by Robson, and a Stackelberg outcome is also obtained.

${ }^{2}$ Throughout the paper we consider that collusive outcomes describe situations where both firms produce less than their Cournot-Nash quantities. We also consider that Stackelberg warfare describes a situation where both firms produce more than their Cournot-Nash outputs.

${ }^{3}$ As we have seen the prediction of Stackelberg equilibria rests on equilibrium selection arguments. Simultaneous-move Cournot-Nash equilibria typically exist, however, they do not survive the application of equilibrium refinements.

${ }^{4}$ Bagwell (1995) points out that the theoretical prediction of Stackelberg outcomes crucially depends on the perfect observability of the Stackelberg leader's action. However, the experiments assume perfect observability, which rules out this explanation.
} 
leader's quantity is risky compared with playing the Cournot-Nash quantity. ${ }^{5}$

It is possible to think of explanations for some aspects of the empirical evidence. However, it is much harder to explain all of the experimental findings. For example, the risk-payoff equilibrium selection argument may explain why simultaneous-move outcomes are more frequently played than Stackelberg outcomes. However, it cannot explain the emergence of collusive outcomes or Stackelberg warfare. It is also not clear how this explanation can account for the fact that simultaneous-move play can take place in the second production period in Hamilton and Slutsky's action commitment game.

The gap between the theory and the experimental evidence is the main motivation behind this paper. To bridge this gap, I generalize Hamilton and Slutsky's action commitment game by assuming that players are averse to inequality in payoffs. An inequity averse player dislikes advantageous inequity (i.e. feels compassion towards his rival if the rival has lower profits) and also dislike disadvantageous inequity (i.e. feels envy towards the rival if the rival has higher profits). ${ }^{6}$ The paper derives the predictions of this explanation for Hamilton and Slutsky's endogenous timing games and compares the predictions to the empirical evidence.

Inequity aversion has been shown to explain a broad range of data for many different games. The clearest evidence for these type of preferences comes from bargaining and trust games. For example, in ultimatum games offers are usually much more generous than predicted by equilibrium, and low offers are often rejected. According to the inequity aversion explanation, these offers are consistent with an equilibrium in which players make offers knowing that other players may reject allocations that appear unfair. Huck et al. (2002), Müller (2006), and Fonseca et al. (2006) suggest that inequity aversion may also explain behavior in endogenous timing games. However, these papers do not formalize this explanation.

The paper shows that relatively high levels of inequity aversion rule out asymmetric equilibria in Hamilton and Slutsky's action commitment game. In other words, relatively high levels of inequity aversion favor simultaneous-move play over sequential play. The intuition for this result is straightforward. For relatively high levels of inequity aversion, playing leader type outcomes leads to inequity costs that are larger than the material benefits of leadership. ${ }^{7}$

The paper also shows that inequity aversion gives rise to a continuum of symmetric equilibria in Hamilton and Slutsky's action commitment game. Clearly, if an inequity averse player knows that his rival will produce the Cournot-Nash quantity, then his best reply is to produce the Cournot-Nash quantity since any other output level reduces profits and increases inequity costs. Now, if an inequity averse player knows that his rival will produce an output level that is somewhat lower (higher) than the Cournot-Nash quantity, then his best reply

\footnotetext{
${ }^{5}$ See Harsanyi and Selten (1988) for a discussion of risk-payoff dominance considerations.

${ }^{6}$ To model inequity aversion I make use of Fehr and Schmidt's (1999) approach.

${ }^{7}$ Relatively low levels of inequity aversion do not rule out asymmetric equilibria. In fact, as inequity aversion vanishes, the set equilibria of each game converge to the set of equilibria of the standard game where players are assumed to care only about material payoffs.
} 
is to produce exactly the same quantity as the rival since producing a higher (lower) quantity increases profits by less than the cost from advantageous (disadvantageous) inequity.

The previous paragraph shows us that inequity aversion may lead both players to produce less than the Cournot-Nash quantity. This happens whenever players have a relatively high level of compassion and are able to coordinate on a "collusive outcome." Similarly, inequity aversion may lead both players to produce more than the Cournot-Nash quantity. This happens whenever players have a relatively high level of envy that leads to Stackelberg warfare. Thus, if a population is composed of players with heterogeneous preferences and these individuals are matched in pairs to play endogenous timing games, then heterogeneity in behavior is to be expected.

The paper argues that inequity aversion is able to explain most experimental findings on endogenous timing games. Inequity aversion can rule out sequential play and give rise to a continuum of simultaneous-move symmetric outcomes. Inequity aversion can explain collusive outcomes and Stackelberg warfare. Additionally, inequity aversion also explains why followers seem to punish leaders. If inequity aversion is relatively low and there is sequential play, then the leader will feel compassion towards the follower and the follower will feel envious of the leader. A compassionate leader will produce less than a selfish leader, and an envious follower will produce more than a selfish follower. This is exactly what the data shows in Huck et al.'s (2002) experiment.

The paper proceeds as follows. Section 2 reviews the evidence. Section 3 describes Hamilton and Slutsky's model and its results. Section 4 extends the model by assuming that players can be averse to inequity and studies the consequences of this assumption. Section 5 summarizes the predictions of inequity aversion and compares them to the empirical evidence. Section 6 discusses the findings. Section 7 concludes the paper. Proofs of propositions are in the Appendix available on the JEBO website.

\section{Experimental Evidence}

Huck et al. (2002) test experimentally the predictions of Hamilton and Slutsky's action commitment game. In the experiment they use the linear inverse demand function

$$
P\left(q^{1}+q^{2}\right)=\max \left\{30-\left(q^{1}+q^{2}\right), 0\right\},
$$

and they assume that costs of production are linear and given by $C^{i}\left(q^{i}\right)=$ $6 q^{i}, i=1,2$. According to this specification, the predictions of Hamilton and Slutsky (1990) are as follows. The Stackelberg leader produces in period one the quantity $S=12$, and the Stackelberg follower produces in period two the quantity $R(S)=6$. The simultaneous-move Cournot-Nash quantities are played in period one and are given by $\left(N^{1}, N^{2}\right)=(8,8)$. The collusive quantities are $\left(C^{1}, C^{2}\right)=(6,6)$. Huck et al. (2002) ran an experiment with a large payoff matrix where subjects could pick an integer quantity from 3 to 15 units. They also ran an experiment with a small payoff matrix where subjects could select a 
quantity from the set $\{6,8,12\}$. Table I (taken from Huck et al. (2002)) displays the experimental results on an aggregate level for both the large and the small payoff matrices.

Table I

\begin{tabular}{lllll}
\hline \hline & & Explicit & Both firms & \\
& In period 1 & followers & in period 2 & Total \\
\hline Large payoff matrix & & & & \\
Average quantity & 9.15 & 8.93 & 8.40 & 17.70 \\
Standard deviation & 1.91 & 1.75 & 1.67 & 1.93 \\
Number of observations & 543 & 207 & 140 & 890 \\
\hline Small payoff matrix & & & & \\
Average quantity & 8.65 & 7.89 & 7.60 & 16.05 \\
Standard deviation & 2.24 & 1.22 & 1.21 & 1.64 \\
Number of observations & 136 & 94 & 170 & 400 \\
\hline \hline
\end{tabular}

Table I shows us that in the experiment with the large payoff matrix, in 543 out of 890 cases $(61 \%)$, subjects committed themselves in period 1 . In the remaining cases subjects decided to wait. Those who decided to produce in the first period produced on average 9.15 units, which is less than the Stackelberg leader's quantity of 12 units. Those who decided to wait and produce in the second period after having observed that the rival produced in the first period produced an average output of 8.93 units, which is larger than the Stackelberg follower's output of 6 units. This seems to imply that Stackelberg followers exhibit aversion to disadvantageous inequity since they are willing to produce more than the material best reply to reduce the payoff of the Stackelberg leader. When both subjects decided to wait, 140 out of 890 cases (18\%), their average output was 8.40 units, which is similar to the Cournot-Nash quantity. Table I also shows us that in the experiment with the small payoff matrix, only in 136 out of 400 cases (34\%) did subjects commit themselves in the first period. Both subjects decided to wait in 170 out of 400 cases (42\%). Average outputs are slightly smaller than those observed with the large payoff matrix.

Huck et al. (2002) also find that explicit followers' observed responses in the experiment with the large payoff matrix have a curious pattern. The continuous theoretical best reply function is given by $q^{F}=12-0.5 q^{L}$. On average, the observed responses of followers have a negative slope when the leaders produce fewer than 7 units or more than 12 units. However, when leaders produces between 7 and 12 units the responses of followers have a positive slope. ${ }^{8}$ Table II summarizes market outcomes in terms of absolute and relative frequencies for the experiment with the large payoff matrix.

Table II

\footnotetext{
${ }^{8}$ See Fig. 2 in Huck et al. (2002). This finding is replicated in Huck et al. (2001) in a game where the roles of leader and follower are exogenously assigned.
} 


\begin{tabular}{llllll}
\hline \hline & & \multicolumn{2}{l}{$\begin{array}{l}\text { Number } \\
\text { Market outcome }\end{array}$} & Type & \multicolumn{2}{l}{$\begin{array}{l}\text { Number of cases } \\
\text { incl. quant. 9 and 11 }\end{array}$} \\
\hline Cournot & Equilibrium & 64 & $14.4 \%$ & 93 & $20.9 \%$ \\
Stackelberg & Equilibrium & 24 & $5.4 \%$ & 33 & $7.4 \%$ \\
Stackelberg/Cournot & Coord. failure & 27 & $6.1 \%$ & 41 & $9.2 \%$ \\
Stackelberg warfare & Coord. failure & 21 & $4.7 \%$ & 30 & $6.7 \%$ \\
Stackelberg punished & Other & 43 & $9.7 \%$ & 55 & $12.4 \%$ \\
Collusion (successful) & Other & 25 & $5.6 \%$ & 25 & $5.6 \%$ \\
Collusion (exploited) & Other & 19 & $4.3 \%$ & 19 & $4.3 \%$ \\
Collusion (failed) & Coord. failure & 34 & $7.6 \%$ & 41 & $9.2 \%$ \\
Others & & 188 & $42.2 \%$ & 108 & $24.3 \%$ \\
Sum & & 445 & $100 \%$ & 445 & $100 \%$ \\
\hline \hline
\end{tabular}

We see from Table II that the Cournot equilibrium is the most frequent outcome since it represents $14.4 \%$ of all outcomes, $20.9 \%$ of all outcomes when the quantity 9 is counted as a Cournot action. The Stackelberg equilibria occur only rarely since they represent $5.4 \%$ of all outcomes, $7.4 \%$ of all outcomes when the quantity 11 is counted as a Stackelberg leader action. Coordination failure occurs in $10.8 \%$ of all outcomes, $15.9 \%$ when 9 is counted as Cournot and 11 as Stackelberg leader actions. In the experiment with the small payoff matrix, Cournot outcomes become much more frequent (45\% vs. 20.9\%). The frequencies of successful and unsuccessful collusion are more similar than the ones with the large payoff matrix. Coordination failure becomes less important ( $4.5 \%$ vs. $15.9 \%)$. Endogenous Stackelberg equilibria occur even less frequently (5\% vs. $7.4 \%)$ than with the large matrix. The results with the small payoff matrix rule out the possibility that complexity was responsible for the results obtained with the large payoff matrix. Thus, the results with the small payoff matrix reinforce the idea that subjects prefer symmetric Cournot outcomes to asymmetric outcomes.

Fonseca et al. (2005) show that Huck et al. (2002)'s findings are robust to cost asymmetries. They find that low cost firms are not able to use their cost advantage to become Stackelberg leaders and that Cournot play is modal. ${ }^{9}$ Fonseca et al. (2006) test experimentally Hamilton and Slutsky' s observable delay game. In this game two firms bindingly announce a production period (one out of two periods) and then produce in the announced sequence. Hamilton and Slutsky show that this game has a unique symmetric equilibrium where firms produce only in the first period. Fonseca et al. (2006) find that there is delay in players' production decisions.

\footnotetext{
${ }^{9}$ Van Damme and Hurkens (1999) analyze an endogenous timing game with cost differences between firms. In their model a unique Stackelberg equilibrium is selected with the most efficient firm being the Stackelberg leader.
} 


\section{The Model}

In Hamilton and Slutsky's action commitment game, firms can only produce in one of two production periods. In the first period firms can either produce some quantity or decide to wait. If and only if a firm decides to wait, it is informed about the rival's first period action and after that can choose its second-period production.

Following Hamilton and Slutsky, define the single-period best reply of firm $i$ as $^{10}$

$$
R^{i}\left(q^{j}\right)=\arg _{q^{i}} \max \left[P\left(q^{i}+q^{j}\right)-c\right] q^{i}, i \neq j=1,2 .
$$

I assume that these best replies are well behaved. ${ }^{11}$ Let $\left(N^{1}, N^{2}\right)$ be the unique single-period Cournot-Nash equilibrium outcome. When firm $i$ produces $q^{i}$ in the first period, and firm $j$ produces its best reply in the second period the profit function of firm $i$ is given by

$$
\pi_{L}^{i}=\left[P\left(q^{i}+R^{j}\left(q^{i}\right)\right)-c\right] q^{i}, i \neq j=1,2 .
$$

For simplicity, I assume that only one Stackelberg point exists for each firm. Denote these points by $S^{i}, i=1,2$, with

$$
S^{i}=\arg _{q^{i}} \max \left[P\left(q^{i}+R^{j}\left(q^{i}\right)\right)-c\right] q^{i}, i \neq j=1,2 .
$$

Hamilton and Slutsky show that this game has three subgame perfect Nash equilibria (SPNE): one simultaneous-move Cournot equilibrium where both firms produce the Cournot-Nash quantities in the first production period, ${ }^{12}$ and two sequential-move Stackelberg equilibria where one firm produces the Stackelberg leader's quantity in the first production period and the other firm produces the Stackelberg follower's quantity in the second production period. ${ }^{13}$ Thus, the set of equilibria in Hamilton and Slutsky's game is given by

$$
E_{H S}=\left\{\left(q_{1}^{1}, q_{1}^{2}\right)=(N, N)\right\} \cup\left\{\left(q_{1}^{1}, q_{2}^{2}\right)=(S, R(S))\right\} \cup\left\{\left(q_{2}^{1}, q_{1}^{2}\right)=(R(S), S)\right\} .
$$

The Stackelberg equilibria are in undominated strategies. The simultaneousmove equilibrium uses weakly dominated strategies since playing the CournotNash quantity in the first production period is dominated by waiting to play after one's rival.

\footnotetext{
10 The reaction function corrresponds to a standard single production period Cournot model.

${ }^{11} \mathrm{By}$ this we mean, $-1 \leq \partial R^{i}\left(q^{j}\right) / \partial q^{i}<0$. The second condition ensures the existence of a unique single-period Cournot-Nash equilibrium. A set of sufficient conditions for $R^{i}$ functions to be "well-behaved" is that $P\left(q^{i}+q^{j}\right)$ is strictly positive on some bounded interval $(0, \bar{Q})$ on which it is twice continuously differentiable, strictly decreasing, and concave, with $P\left(q^{i}+q^{j}\right)=0$ for $q^{i}+q^{j} \geq \bar{Q}$.

${ }^{12}$ Both firms producing the Cournot-Nash quantities in the second production period is not an equilibrium since each firm would do better to deviate unilaterally and produce the Stackelberg leader's quantity in the first production period.

${ }^{13}$ A firm producing the Stackelberg leader's quantity, $S^{i}$, in the first production period and the opponent producing the Stackelberg follower's quantity, $R^{j}\left(S^{i}\right)$, in the first production period is not an equilibrium because the leader would rather produce its best response to the Stackelberg follower's quantity, that is, $R^{i}\left(R^{j}\left(S^{i}\right)\right)$.
} 


\section{Inequity Aversion}

Many experiments indicate that individuals are motivated not only by material self-interest, but also by the distribution of payoffs. I incorporate this possibility in Hamilton and Slutsky's game by assuming that firms are averse to inequality in profits. To model this, I make use of Fehr and Schmidt's approach. Thus, I assume that firm $i$ 's payoff is given by

$$
U^{i}\left(\pi^{i}, \pi^{j}\right)=\pi^{i}-\left[\alpha_{i} \max \left(\pi^{j}-\pi^{i}, 0\right)+\beta_{i} \max \left(\pi^{i}-\pi^{j}, 0\right)\right], i \neq j=1,2 .
$$

The terms in the square bracket are the payoff effects of disadvantageous and advantageous inequity, respectively. When $\pi^{j}>\pi^{i}$ firm $i$ feels envy towards firm $j$; this is the disadvantageous inequity term. When $\pi^{j}<\pi^{i}$ firm $i$ feels compassion towards firm $j$; this is the advantageous inequity term. Fehr and Schmidt assume that $\alpha_{i}$ and $\beta_{i}$ are nonnegative, that $\alpha_{i}>\beta_{i}$ (the dislike of disadvantageous inequity is stronger than that of advantageous inequity), and that $\beta_{i}$ is smaller than 1 . I assume that $\alpha_{i}$ is nonnegative and that $\beta_{i} \in[0,1 / 2] .{ }^{14}$

Santos-Pinto (2006) shows that the single-period best reply of firm $i$ in the presence of inequity aversion is defined by

$$
R^{i}\left(q^{j}\right)=\left\{\begin{array}{lr}
s^{i}\left(q^{j}\right), & 0 \leq q^{j} \leq q\left(\beta_{i}\right) \\
q^{j}, & q\left(\beta_{i}\right) \leq q^{j} \leq q\left(\alpha_{i}\right) \\
t^{i}\left(q^{j}\right), & q\left(\alpha_{i}\right) \leq q^{j}
\end{array},\right.
$$

where

$$
\begin{aligned}
& s^{i}\left(q^{j}\right)=\arg _{q^{i}} \max \left(1-\beta_{i}\right)\left[P\left(q^{i}+q^{j}\right)-c_{i}\right] q^{i}+\beta_{i}\left[P\left(q^{i}+q^{j}\right)-c_{j}\right] q^{j}, \\
& t^{i}\left(q^{j}\right)=\arg _{q^{i}} \max \left(1+\alpha_{i}\right)\left[P\left(q^{i}+q^{j}\right)-c_{i}\right] q^{i}-\alpha_{i}\left[P\left(q^{i}+q^{j}\right)-c_{j}\right] q^{j},
\end{aligned}
$$

$q\left(\beta_{i}\right)$ is the solution to $\left(1-\beta_{i}\right)\left[P(2 q)-c_{i}\right]+P^{\prime}(2 q) q=0$, and $q\left(\alpha_{i}\right)$ is the solution to $\left(1+\alpha_{i}\right)\left[P(2 q)-c_{i}\right]+P^{\prime}(2 q) q=0$.

The main difference between this best reply and the standard one is that with inequity aversion there is a range of a rival's output levels for which the best reply of a firm is to produce the same as the rival. That happens around the Cournot-Nash equilibrium quantity of the standard simultaneous-move game. In other words, the best reply has a positive slope for output levels of the rival close to the Cournot-Nash level and a negative slope for the remaining output levels of the rival. As we have seen, Huck et al.'s (2002) experiment on Hamilton and Slutsky's action commitment game finds evidence for this type of best reply.

Santos-Pinto also shows that the set of Nash equilibria of the single-period symmetric Cournot duopoly game when firms are averse to inequity is given by

$$
E^{I A}=\left\{\left(q^{1}, q^{2}\right): q^{1}=q^{2}, \text { and } N\left(\beta_{1}, \beta_{2}\right) \leq q^{i} \leq N\left(\alpha_{1}, \alpha_{2}\right), i=1,2\right\}
$$

\footnotetext{
${ }^{14}$ The assumption that $\beta_{i}$ is smaller than $1 / 2$ implies that a firm never cares more about the profit of its rival than about its own profit. This assumption also rules out equilibria of the single period Cournot model where firms produce less than the collusive quantities.
} 
where $N\left(\beta_{1}, \beta_{2}\right)=\max \left[q\left(\beta_{1}\right), q\left(\beta_{2}\right)\right]$, and $N\left(\alpha_{1}, \alpha_{2}\right)=\min \left[q\left(\alpha_{1}\right), q\left(\alpha_{2}\right)\right]$.

This result tells us that inequity aversion between firms gives rise to a continuum of symmetric equilibria in the single-period Cournot duopoly game. The intuition for this result is as follows. Suppose that a firm knows its rival will produce an output level that is close to the Nash equilibrium of the standard single-period Cournot game. If that firm dislikes inequity aversion, then there is a cost in advantageous inequity associated with producing a higher level of output than the rival. Similarly, there is also a cost in disadvantageous inequity associated with producing a smaller output level than the rival. For a range of output levels close to the Nash equilibrium of the standard single-period Cournot game, the profits lost from not matching the rival's output are small while the inequity costs are large. If that is the case, then the firm is better off by producing the same level of output as the rival.

The result also shows that the smallest Nash equilibria of the single-period Cournot game is determined by the lowest level of compassion of the two firms and that the largest Nash equilibria is determined by the lowest level of envy of the two firms. We see from (1) that if both firms have a level of compassion equal to $1 / 2$, then the lowest Nash equilibrium of the single-period Cournot duopoly game with inequity averse firms corresponds to the best collusive outcome.

I will now show that inequity aversion between firms also gives rise to a continuum of symmetric equilibria in Hamilton and Slutsky's game. I assume, without loss of generality, that there is symmetry in the inequity aversion parameters; that is, we take $\alpha_{1}=\alpha_{2}=\alpha$ and $\beta_{1}=\beta_{2}=\beta .{ }^{15}$ Given this assumption, we let $N(\beta)$ denote $N\left(\beta_{1}, \beta_{2}\right)$ and $N(\alpha)$ denote $N\left(\alpha_{1}, \alpha_{2}\right)$.

To characterize the set of equilibria of Hamilton and Slutsky's game with inequity averse firms I need to introduce some notation. Let the Stackelberg leader's quantity in the presence of inequity aversion be denoted by $S^{i}(\alpha, \beta)$, $i=1,2$, and the Stackelberg follower's quantity by $R^{j}\left(S^{i}(\alpha, \beta)\right), j \neq i$. If firm $i$ is the Stackelberg leader, then it picks the point in $R^{j}\left(q^{i}\right)$ that maximizes its payoff. The existence of inequity aversion implies that the Stackelberg leader's quantity is defined as

$$
S^{i}(\alpha, \beta)=\left\{\begin{array}{l}
N(\beta), \text { if } U^{i}\left(L^{i}(\alpha, \beta), t^{j}\left(L^{i}(\alpha, \beta)\right)\right) \leq U^{i}(N(\beta), N(\beta)) \\
L^{i}(\alpha, \beta), \text { otherwise }
\end{array}\right.
$$

and the Stackelberg follower's quantity by

$R^{j}\left(S^{i}(\alpha, \beta)\right)=\left\{\begin{array}{l}N(\beta), \text { if } U^{i}\left(L^{i}(\alpha, \beta), t^{j}\left(L^{i}(\alpha, \beta)\right)\right) \leq U^{i}(N(\beta), N(\beta)) \\ t^{j}\left(L^{i}(\alpha, \beta)\right), \text { otherwise }\end{array}\right.$

where

$$
\begin{aligned}
L^{i}(\alpha, \beta)=\arg _{q^{i} \geq N(\alpha)} \max (1-\beta)\left[P\left(q^{i}+t^{j}\left(q^{i}\right)\right)-c_{i}\right] q^{i} \\
+\beta\left[P\left(q^{i}+t^{j}\left(q^{i}\right)\right)-c_{j}\right] t^{j}\left(q^{i}\right),
\end{aligned}
$$

\footnotetext{
${ }^{15}$ If we assume that $\beta_{1} \neq \beta_{2}$ and/or $\alpha_{1} \neq \alpha_{2}$ the game becomes asymmetric. This compli-
} cates the analysis without providing additional insights on the problem. 
$j \neq i=1,2$. We see from (3) and (4) that the presence of inequity aversion implies that the Stackelberg point is either point $(N(\beta), N(\beta))$, the smallest Nash equilibrium of the simultaneous-move game, or point $\left(L^{i}(\alpha, \beta), t^{j}\left(L^{i}(\alpha, \beta)\right)\right)$. If the payoff of the smallest Nash equilibrium of the simultaneous move game is greater than the payoff of point $\left(L^{i}(\alpha, \beta), t^{j}\left(L^{i}(\alpha, \beta)\right)\right)$, then $(N(\beta), N(\beta))$ is the Stackelberg point. If the payoff of the smallest Nash equilibrium of the simultaneous move game is smaller than the payoff of point $\left(L^{i}(\alpha, \beta), t^{j}\left(L^{i}(\alpha, \beta)\right)\right)$, then $\left(L^{i}(\alpha, \beta), t^{j}\left(L^{i}(\alpha, \beta)\right)\right)$ is the Stackelberg point. In this case, firm $i$ produces more than firm $j$ since $L^{i}(\alpha, \beta)<t^{j}\left(L^{i}(\alpha, \beta)\right)$. This implies that the profit of firm $i$ is larger than that of firm $j$, and therefore firm $i$ feels compassion towards firm $j$ whereas firm $j$ feels envy towards firm $i$. When the Stackelberg point is $\left(L^{i}(\alpha, \beta), t^{j}\left(L^{i}(\alpha, \beta)\right)\right)$, it is a function of $\alpha$ and of $\beta$. The Stackelberg leader's output $L^{i}(\alpha, \beta)$ is decreasing in $\alpha$ and $\beta$ whereas the Stackelberg follower's output $t^{j}\left(L^{i}(\alpha, \beta)\right)$ is increasing in $\alpha$ and $\beta$. An increase in $\alpha$, the degree of envy, leads the follower to raise production, and this in turn implies a lower quantity for the leader. An increase in $\beta$, the degree of compassion, leads the leader to reduce its output, and this in turn implies a higher quantity for the follower.

Proposition 1 characterizes the set of equilibria of Hamilton and Slutsky's action commitment game for relatively high levels of inequity aversion between firms.

Proposition 1 If $U^{i}(N(\beta), N(\beta))>U^{i}\left(S^{i}(\alpha, \beta), t^{j}\left(S^{i}(\alpha, \beta)\right)\right), i=1,2$, then the set of equilibria of Hamilton and Slutsky's action commitment game with inequity averse firms is given by

$$
\begin{aligned}
E_{H S}^{I A}=\left\{\left(q_{1}^{1}, q_{1}^{2}\right): q_{1}^{1}=q_{1}^{2}, \text { and } N(\beta) \leq q_{1}^{i} \leq\right. & N(\alpha), i=1,2\} \\
& \cup\left\{\left(q_{2}^{1}, q_{2}^{2}\right)=(N(\beta), N(\beta))\right\} .
\end{aligned}
$$

This result tells us that if the degree of inequity aversion between firms is relatively high, then Hamilton and Slutsky's action commitment game has a continuum of symmetric SPNE. In this set of equilibria both firms produce in the first period, and each firm produces a quantity between the smallest and the largest Nash equilibrium quantity of the single-period Cournot duopoly game with inequity averse firms. Thus, if the degree of inequity aversion between firms is relatively high, then the set of SPNE of Hamilton and Slutsky's action commitment game coincides with the set of Nash equilibria of the single-period Cournot duopoly game. ${ }^{16}$

The intuition for this result is as follows. Inequity aversion between firms, whether it is high or low, gives rise to a continuum of symmetric equilibria both in the single-period Cournot game as well as in Hamilton and Slutsky's game. Additionally, if inequity aversion is relatively high, that is, $\alpha$ and $\beta$ are such that

\footnotetext{
${ }^{16}$ This is true for any symmetric equilibria in $E_{H S}^{I A}$, except the lowest Nash equilibrium of the simultanous-move Cournot game, $(N(\beta), N(\beta))$. Suppose that both firms produce $N(\beta)$ in the second production period. In this case each firm is indifferent between producing $N(\beta)$ in the second production period or in the first.
} 
each firm prefers the smallest Nash equilibrium payoff of the simultaneous move game, $U^{i}(N(\beta), N(\beta))$ to its payoff as the Stackelberg leader, then there are no Stackelberg equilibria. Thus, the only equilibria of Hamilton and Slutsky's action commitment game with relatively high levels of inequity aversion between firms are the simultaneous-move equilibria. The fact that in Hamilton and Slutsky's action commitment game firms can only produce in one of the two periods implies that production in any simultaneous move-equilibria takes place in the first period.

The next result characterizes the set of equilibria in Hamilton and Slutsky's action commitment game for relatively low levels of inequity aversion.

Proposition 2 If $\alpha$ and $\beta$ are such that the Stackelberg point exists and $U^{i}\left(S^{i}(\alpha, \beta), R^{j}\left(S^{i}(\alpha, \beta)\right)\right)>U^{i}(N(\beta), N(\beta)), i=1,2$, then the set of equilibria of Hamilton and Slutsky's action commitment game with inequity averse firms is given by

$$
\begin{gathered}
E_{H S}^{I A}=\left\{\left(q_{1}^{1}, q_{1}^{2}\right): q_{1}^{1}=q_{1}^{2} \text {, and } N(\beta) \leq q_{1}^{i} \leq N(\alpha), i=1,2\right\} \\
\cup\left\{\left(q_{1}^{1}, q_{2}^{2}\right)=\left(L^{1}(\alpha, \beta), t^{2}\left(L^{1}(\alpha, \beta)\right)\right)\right\} \cup\left\{\left(q_{2}^{1}, q_{1}^{2}\right)=\left(t^{1}\left(L^{2}(\alpha, \beta)\right), L^{2}(\alpha, \beta)\right)\right\} .
\end{gathered}
$$

This result tells us that if the degree of inequity aversion between firms is relatively low, then Hamilton and Slutsky's action commitment game has a continuum of symmetric SPNE and two asymmetric SPNE. In any symmetric equilibria both firms produce in the first period, and each firm produces a quantity between the smallest and the largest Nash equilibrium quantity of the single-period Cournot duopoly game with inequity averse firms. The asymmetric equilibria are of the leader-follower type with one firm producing the Stackelberg leader's quantity in the first production period and the other firm producing the Stackelberg follower's quantity in the second period. The difference here, in comparison with Hamilton and Slutsky's action commitment game with selfish firms, is that a compassionate leader produces less than a selfish leader and a envious follower produces more than a selfish follower.

Santos-Pinto shows that the point $(N(\beta), N(\beta))$ is decreasing with $\beta$; that is, the smallest symmetric equilibrium of the single-period Cournot duopoly game with inequity averse firms is decreasing with an increase in compassion. This means that a decrease in compassion moves the set of symmetric equilibrium outcomes closer to the best collusive outcome (the outcome obtained when $\beta=$ $1 / 2$ ). In contrast, the largest symmetric equilibrium of the single-period Cournot duopoly game with inequity averse firms is increasing with an increase in envy.

As $\alpha$ and $\beta$ converge to zero the impact of inequity aversion vanishes since the set of symmetric equilibria in Hamilton and Slutsky's game with inequity averse players collapses to the Nash equilibria of the single-period Cournot game and the point $\left(S^{i}(\alpha, \beta), t^{j}\left(S^{i}(\alpha, \beta)\right)\right)$ converges to $\left(S^{i} ; R^{j}\left(S^{i}\right)\right), i=1,2 .{ }^{17}$

\footnotetext{
${ }^{17}$ As $\alpha$ converges to zero the point $(N(\alpha), N(\alpha))$ converges to $(N, N)$, and as $\beta$ converges to zero the point $(N(\beta), N(\beta))$ converges to $(N, N)$.
} 


\section{Summary and Comparison}

In this section I summarize the predictions of the inequity aversion explanation and compare them to the experimental evidence. Recall that the experimental evidence on Hamilton and Slutsky's action commitment game tells us that (i) Stackelberg outcomes are rare, (ii) simultaneous-move Cournot outcomes are the most frequent outcomes, (iii) simultaneous-move outcomes are often played in the second production period, and (iv) behavior is quite heterogeneous; in some cases followers punish leaders, in other cases collusive outcomes are played, and in other cases Stackelberg warfare is observed.

Table III below summarizes the predictions for Hamilton and Slutsky's action commitment game.

Table III

\begin{tabular}{cccccccc}
\hline \hline \multicolumn{7}{c}{ Hamilton and Slutsky's Action Commitment Game } \\
\hline & $\begin{array}{c}\text { Sym. } \\
\text { eq. }\end{array}$ & $\begin{array}{c}\text { Stack. } \\
\text { eq. }\end{array}$ & $\begin{array}{c}\text { Coll. } \\
\text { out. }\end{array}$ & $\begin{array}{c}\text { Stack. } \\
\text { warf. }\end{array}$ & $\begin{array}{c}\text { Punish } \\
\text { leader }\end{array}$ & $\begin{array}{c}\text { Time } \\
\text { prod. }\end{array}$ & $\begin{array}{c}\text { Cournot } \\
\text { in P2 }\end{array}$ \\
\hline $\begin{array}{c}\text { Ineq. Av. } \\
\text { High }\end{array}$ & Many & - & Yes & Yes & - & P1 & No \\
Low & Many & - & No & No & - & P1 & No \\
& - & Two & - & - & Yes & P1\&P2 & - \\
\hline \hline
\end{tabular}

Table III shows us that inequity aversion is able to explain most of the experimental evidence on Hamilton and Slutsky's action commitment game. First, relatively high levels of inequity aversion imply that Hamilton and Slutsky's action commitment game has only simultaneous-move symmetric outcomes where both firms produce in the first production period. ${ }^{18}$ When inequity aversion is low there is a continuum of simultaneous-move symmetric equilibria, but there are also two Stackelberg equilibria with sequential play.

Second, inequity aversion can explain collusive outcomes in Hamilton and Slutsky's action commitment game. This happens whenever both players have a relatively high level of inequity aversion and are able to coordinate on the collusive outcome.

Third, if inequity aversion is relatively high, there are no Stackelberg outcomes in Hamilton and Slutsky's action commitment game. Thus, for Stackelberg outcomes to be played, players must have relatively low levels of inequity aversion.

Fourth, if inequity aversion is relatively low and players play the Stackelberg outcome, then the model predicts that the Stackelberg leader will feel compassion towards the follower and that the Stackelberg follower will feel envy towards the leader. This implies that a compassionate leader produces less than a selfish

\footnotetext{
${ }^{18}$ Among all the symmetric equilibria in Hamilton and Slutsky's game with inequity averse players, the Cournot-Nash equilibrium of the game with selfish players may be the one that is most frequently played. This happens because this equilibrium is always a subgame perfect Nash equilibrium of the game whether players are averse to inequity or not. That is not the case with the other symmetric equilibria.
} 
leader and that an envious follower produces more than a selfish follower. This pattern is consistent with the evidence in Huck et al. (2002). Table III shows that in the experiment with the large payoff matrix, explicit followers produce on average 8.93 units. This is significantly higher than the Stackelberg follower's quantity of 6 units. ${ }^{19}$

Fifth, the fact that there exists a continuum of symmetric equilibria and that firms must coordinate by moving simultaneously in the first production period is also consistent with the empirical finding of coordination failure in Hamilton and Slutsky's action commitment game.

The only empirical finding in Hamilton and Slutsky's action commitment game that inequity aversion is unable to explain is simultaneous-move CournotNash outcomes in the second production period. ${ }^{20}$

\section{Discussion}

This section shows that inequity aversion is also able to explain most of the experimental evidence on Saloner's duopoly game. It discusses informally the robustness of the results to alternative specification of inequity aversion. It shows that if firms have concerns for status rather than being inequity averse, then one cannot explain why collusive outcomes are played in experiments on Hamilton and Slutsky's game. Finally, it considers the implications of introducing private information about players' types (selfish or inequity averse).

\subsection{Saloner's Duopoly Game}

Saloner (1987) analyzes a duopoly with two periods where firms can produce in both periods before the market clears. In the first period firms simultaneously choose initial production levels. The choices of the first period are observed and then additional non-negative second period outputs are chosen simultaneously. Saloner shows that if production costs are the same across both periods, then

\footnotetext{
${ }^{19}$ The same thing happens in the experiment with the small payoff matrix. On average, explicit followers in the experiment with the small payoff matrix produce 7.89. Huck et al. (2002) do not display data for explicit leaders. However, we can use the data in the small payoff matrix to have an idea of the average quantity of explicit leaders (in the small payoff matrix most players who produce in the first period are explicit leaders; this is not the case in the large payoff matrix). In the experiment with the small payoff matrix there are 136 players who produce in the first period, of whom 94 are explicit leaders and 42 are players who produce simultaneously. If the 94 explicit leaders produced the leader's quantity, 12 units, and the other 42 players the Cournot-Nash quantity, the average output of these 136 players should be equal to 10.76. In contrast, the data shows that the average output of these 136 players is significantly lower: 8.65 units. This tells us that, on average, explicit leaders produce substantially less than the Stackelberg quantity.

${ }^{20}$ Fonseca et al. (2006) test experimentally Hamilton and Slutsky's observable delay game. In this game two firms bindingly announce a production period (one out of two periods) and then produce in the announced sequence. This game has a unique symmetric equilibrium where firms produce only in the first period. Fonseca et al. (2006) find that there is a delay in players' production decisions. The findings in this paper show that inequity aversion is also not able to explain delay in Fonseca et al. (2006).
} 
there is a continuum of equilibria: any point on the outer envelope of the best replies between the firm's Stackelberg outputs is attainable with a SPNE. Additionally, in all of these equilibria production takes place only in the first period. However, Ellingsen (1995) shows that only the two Stackelberg equilibria in Saloner's game survive elimination of weakly dominated strategies. ${ }^{21}$

Müller tests the predictions of Saloner's game extended by Ellingson. He finds that (i) Stackelberg outcomes are extremely rare, (ii) simultaneous-move symmetric outcomes are modal, (iii) sometimes collusive outcomes are observed, (iv) there is production in both periods with $84 \%$ of production taking place in the first period, (v) subjects seem to attempt to balance market shares in the second production period, and (vi) subjects do not produce more than the Stackelberg follower's quantity in the first period.

It turns out that inequity aversion is also able to explain most of the experimental evidence on Saloner's game. ${ }^{22}$ First, relatively high levels of inequity aversion imply that Saloner's game has a continuum of simultaneous-move symmetric equilibria. When inequity aversion is low there is still a continuum of simultaneous-move symmetric equilibria, but there is also a continuum of asymmetric equilibria where play may be sequential.

Second, collusive outcomes are played whenever two subjects with a high degree of compassion are matched to play the game and are able to coordinate on the collusive outcome. Stackelberg warfare happens whenever two subjects with a high degree of envy are matched to play the game and both produce more than the Cournot-Nash quantities.

Third, relatively high levels of inequity aversion rule out Stackelberg outcomes. However, relatively low levels of inequity aversion do not. Thus, whenever two subjects with a relatively low level of inequity aversion are matched to play the game, we may have Stackelberg equilibria.

Fourth, inequity aversion is also able to explain the fact that subjects produce in both periods. If subjects are unable to coordinate in one of the multiple symmetric equilibria in the first production period, then they have an incentive to produce in the second production period to attain coordination before the market clears. This explains why subjects seem to attempt to balance market shares in the second period.

The only empirical finding in Saloner's game that the inequity aversion explanation seems unable to account for is that firms do not produce more than the Stackelberg follower's quantity in the first production period.

\footnotetext{
${ }^{21}$ Several papers have suggested ways to reduce the set of equilibria in Saloner's model by modifying the structure of the game. For example, Robson introduces discounting between periods, Pal (1991) introduces cost asymmetries between periods, and Maggi (1996) introduces uncertainty about demand.

${ }^{22}$ The theoretical predictions that follow from incorporating inequity aversion into Saloner's model are available upon request.
} 


\subsection{Differentiable Inequity Aversion}

As we have seen, Fehr and Schmidt's (1999) model of inequity aversion is able to explain several experimental findings in endogenous timing games. However, Fehr and Schmidt's specification is a particular functional form of inequity aversion (it is piecewise linear and non-differentiable). Could it be that the results obtained extend to more general preferences?

Santos-Pinto studies the impact of general specifications of inequity aversion on Cournot competition. He shows that for differentiable forms of inequity aversion, the best reply of a firm is always negatively sloped. However, the best reply of an inequity averse firm is smaller (larger) than the best reply of a selfish firm when the rival produces low (high) output levels given that the inequity averse firm feels compassion (envy) towards the rival. This implies that the two Stackelberg equilibria of Hamilton and Slutsky's game with firms with differentiable inequity aversion are much less asymmetric than the two Stackelberg equilibria of the game with selfish firms. Thus, inequity aversion either rules out asymmetric outcomes completely (high levels of piecewise linear inequity aversion) or reduces the degree of asymmetry substantially (high levels of differentiable inequity aversion). ${ }^{23}$

The main difference, by comparison with Fehr and Schmidt's (1999) specification, is that differentiable inequity aversion does not lead to positively sloped best replies over some output range. This means that the continuum of equilibria result is no longer valid for differentiable inequity aversion.

\subsection{Preferences for Status}

It could also be argued that individuals might not dislike inequity, but instead they might enjoy it, at least as long as others are worse off than they are. This type of preference can be interpreted as a concern for status. There is some evidence for status seeking preferences in experimental duopoly games. Huck et al. (2001) find that exogenous Stackelberg leaders produce less than the selfish Stackelberg leader's quantity but more than the Stackelberg leader's quantity predicted by Fehr and Schmidt model of inequity aversion. ${ }^{24}$

The model can be modified to deal with status seeking preferences by maintaining $\alpha$ positive but assuming that $\beta$ is negative. This means that firms are still averse to disadvantageous inequity but like advantageous inequity. Additionally, I assume that $0<-\beta \leq \alpha$; that is, aversion to disadvantageous inequity is (weakly) stronger than the appeal of advantageous inequity.

If a firm cares about status its single period best reply is greater than the single period best reply of a selfish firm. This happens because concerns for status imply that increasing output above the selfish best reply reduces the

\footnotetext{
${ }^{23}$ The set of SPNE of Saloner's game with differentiable inequity aversion is closer to the $45^{\circ}$ degree line than the set of SPNE of Saloner's game with selfish firms.

${ }^{24}$ Huck et al. (2001) show that the exogenous Stackelberg leaders' quantities can be explained only by negative betas. This happens because the distribution of alpha types in the exogenous follower population implies that Stackelberg leaders with positive betas should not produce more than the Cournot quantity.
} 
profits of the rival more than a firm's own profits. This has a first-order favorable impact on the payoff derived from status, but only a second-order unfavorable impact on profits. Thus, concerns for status increase equilibrium output levels.

When $-\beta<\alpha$ the single period best reply of a status seeking firm is similar to the single period best reply of an inequity averse firm: it is negatively sloped for small and large levels of output of the rival, and it consists in producing the same output level as the rival for intermediate output levels of the rival. The novelty here is that the range of output levels where a firm wishes to produce the same output as the rival is strictly above the selfish Cournot-Nash quantity; that is, $R^{i}\left(q^{j}\right)=q_{j}$ for $q(\beta)<q_{j}<q(\alpha)$, with $q^{N S}<q(\beta)$. Thus, if firms are status seeking and $-\beta<\alpha$, then Hamilton and Slutsky's game has a continuum of symmetric equilibria. However, in all these symmetric equilibria firms produce more than the selfish Nash quantity. ${ }^{25}$ It follows from this analysis that if firms care only for status, then we cannot explain why collusive outcomes are observed in experiments on endogenous timing games. ${ }^{26}$

\subsection{Incomplete Information}

This paper assumes that players' preferences are common knowledge. This may not be a reasonable assumption. It could be more reasonable to assume that $100 x$ percent of players in the population are selfish and $100(1-x)$ percent are inequity averse, with $x \in(0,1)$, and that the distribution of types is common knowledge. ${ }^{27}$

Introducing this possibility into Hamilton and Slutsky's endogenous timing game complicates the analysis substantially. Instead of a dynamic game of

\footnotetext{
${ }^{25}$ If $-\beta=\alpha$, then the best reply of a firm with concerns for status is monotonically decreasing in the rival's output just like the best reply of a selfish firm. In this case there is a unique Cournot-Nash equilibrium of the game with status seeking firms where firms' output levels are higher than those in the equilibrium of the game with selfish firms.

${ }^{26}$ To characterize fully the implications of preferences for status on the set of equilibria of Hamilton and Slutsky's game, we also need to understand the impact of status seeking preferences on the Stackelberg equilibria. Recall that the Stackelberg leader's quantity is given by (3) and the follower's quantity by (4). If preferences for status are very strong, then there may not exist asymmetric Stackelberg equilibria. However, if preferences for status are moderate, there exist Stackelberg equilibria where the leader produces more than the follower. In this last case the Stackelberg leader's ouput $L^{i}(\alpha, \beta)$ is decreasing in $\alpha$ but increasing in $\beta$ whereas the Stackelberg follower's output $t^{j}\left(L^{i}(\alpha, \beta)\right)$ is increasing in $\alpha$ and decreasing $\beta$. This happens because an increase in $\alpha$ leads the follower to raise production, and this in turn implies a lower quantity for the leader. However, an increase in $\beta$ leads the leader to increase its output, and this in turn implies a lower quantity for the follower. However, when $-\beta<\alpha$ a leader with status concerns produces less than a selfish leader whereas a follower with status concerns produces more than a selfish follower. Thus, in the game with status seeking firms, Stackelberg equilibria of the type $\left(L^{i}(\alpha, \beta), t^{j}\left(L^{i}(\alpha, \beta)\right)\right)$ are closer to the $45^{\circ}$ degree line than Stackelberg equilibria of the game with selfish firms.

${ }^{27}$ Levine (1998) assumes that a player wants to be kind to a kind person and uses this model to describe experimental results. In order to do so, he assumes that players are uncertain about their rivals' preferences and solves for the equilibrium of incomplete information games. Players draw inferences from the strategies of other people placing higher weight on the material payoffs of people who play nice strategies because playing nice strategies signals that one really is nice.
} 
complete information, we would have a dynamic game with two-sided incomplete information. A player would have private information about his own type (the player knows whether he is selfish or inequity averse) but would be uncertain about the type of the rival. ${ }^{28}$

It is a well-known result that the basic tool for solving dynamic games of incomplete information is the concept of Perfect Bayesian Equilibrium (PBE). There are two basic types of PBE: separating and pooling. ${ }^{29}$ I conjecture the existence of the following separating PBE of Hamilton and Slutsky's game with private information about preferences.

For some parameter values of $\alpha, \beta$ and $x$ there may exist a separating equilibrium where the selfish firm leads and the inequity averse firm follows, thus providing a Stackelberg outcome. In this case the selfish leader will anticipate a punishment by an envious follower and produce less than $S$. If both players are inequity averse, they will both wait and play symmetric simultaneous move outcome in the second production period (this may lead to Stackelberg warfare or collusive outcomes depending on players' levels of envy and compassion). If both players are selfish they will both produce in date 1, yielding bilateral leadership (the worst case of Stackelberg warfare).

For other parameter values of $\alpha, \beta$ and $x$ there may exist a separating equilibrium where the inequity averse firm leads and the selfish firm follows. In this case the leader will be compassionate, producing less than $S$, because it cares about the follower's payoff. If both players are selfish, they will produce the selfish Cournot-Nash quantities in the second production period. If both players are inequity averse they will play a symmetric simultaneous move outcome in the first production period.

This informal discussion shows that introducing private information about players' types (selfish or non-selfish) in Hamilton and Slutsky's game may explain delay in experimental endogenous timing games.

\section{Conclusion}

This paper formalizes the implications of inequity aversion in Hamilton and Slutsky's endogenous timing games. The paper shows that (1) relatively high levels of inequity aversion rule out asymmetric equilibria, and (2) inequity aversion gives rise to a continuum of simultaneous-move equilibria that include the Cournot-Nash outcome, collusive outcomes, and Stackelberg warfare.

The paper also compares the predictions of the model to the experimental evidence on behavior in Hamilton and Slutsky's endogenous timing games. The paper argues that inequity aversion is able to organize most of the experimental evidence on these games, except for delay.

\footnotetext{
${ }^{28}$ Branco (1998) introduces private information about costs into Hamilton and Slutsky's action commitment game.

${ }^{29}$ In a separating equilibrium the two types of the firm that decide to produce in the first period choose different quantities. A pooling equilibrium is an equilibrium in which the two types of the firm that decide to produce in the first period choose the same quantity.
} 


\section{References}

Bagwell, K, 1995. Commitment and observability in games. Games and Economic Behavior 8, 271-280.

Branco, F., 1998. Endogenous timing in a quantity setting duopoly. Working Paper, Universidade Católica Portuguesa.

Ellingsen, T., 1995. On flexibility in oligopoly. Economic Letters 48, 83-89.

Fehr, E., Schmidt, K., 1999. A theory of fairness, competition, and cooperation. Quarterly Journal of Economics 114, 817-868.

Fonseca, M., Huck, S., Normann H.-T., 2005. Playing Cournot although they shouldn't: endogenous timing in experimental duopolies with asymmetric cost. Economic Theory 25, 669-677.

Fonseca, M., Müller, W., Normann, H.-T., 2006. Endogenous timing in duopoly: experimental evidence. International Journal of Game Theory 34, 443-456.

Hamilton, J., Slutsky, S., 1990. Endogenous timing in duopoly games: Stackelberg or Cournot equilibria. Games and Economic Behavior 2, 29-46.

Harsanyi, J., Selten, R., 1988. A general theory of equilibrium selection in games. Cambridge, MA: MIT Press.

Huck, S., Müller, W., Normann, H.-T., 2001. Stackelberg beats Cournot-on collusion and efficiency in experimental markets. Economic Journal 111, 749765 .

Huck, S., Müller, W., Normann, H.-T., 2002. To commit or not to commit: endogenous timing in experimental duopoly markets. Games and Economic Behavior 38, 240-264.

Levine, D., 1998. Modeling altruism and spitefulness in experiments. Review of Economic Dynamics 1, 593-622.

Maggi, G., 1996. Endogenous leadership in a new market. Rand Journal of Economics 27, 641-659.

Müller, W., 2006. Allowing for two production periods in the Cournot duopoly: experimental evidence. Journal of Economic Behavior and Organization 60, 100-111.

Pal, D., 1991. Cournot duopoly with two production periods and cost differentials. Journal of Economic Theory 55, 441-448.

Robson, A., 1990. Duopoly with endogenous strategic timing: Stackelberg regained. International Economic Review 31, 263-274.

Saloner, G., 1987. Cournot duopoly with two production periods. Journal of Economic Theory 42, 183-187.

Santos-Pinto, L., 2006. Reciprocity, inequity aversion, and oligopolistic competition. Working Paper, Universidade Nova de Lisboa.

Van Damme, E., Hurkens, S., 1999. Endogenous Stackelberg leadership. Games and Economic Behavior 28, 105-129. 


\section{Appendix}

Proof of Proposition 1: Let $\left(a^{1}, a^{2}\right)$ be any point in $E_{H S}^{I A}$. Since $a^{2}$ is a best reply to $a^{1}$, neither waiting nor any other output choice in the first production period can raise 2's payoff, and similarly for 1 . Thus, any point $\left(a^{1}, a^{2}\right)$ in $E_{H S}^{I A}$ is an equilibrium. No other outcome can be a subgame perfect equilibrium. Suppose that 1 plays $L^{1}(\alpha, \beta)$ in the first production period and 2 waits and then plays $t^{2}\left(L^{1}(\alpha, \beta)\right)$ in the second production period. This is not an equilibrium since the assumption that $U^{1}(N(\beta), N(\beta))>U^{1}\left(L^{1}(\alpha, \beta), t^{2}\left(L^{1}(\alpha, \beta)\right)\right)$ implies that 1 can do better by producing $N(\beta)$ in the first production period. Similarly, 2 playing $L^{2}(\alpha, \beta)$ in the first production period and 1 playing $t^{1}\left(L^{2}(\alpha, \beta)\right)$ in the second production period is not an equilibrium. A situation where 1 and 2 play $\left(b^{1}, b^{2}\right)$ in the first production period with $\left(b^{1}, b^{2}\right) \notin E_{H S}^{I A}$ is not an equilibrium since at least one of the firms is not playing her best reply to the other firm. If 1 waits, the only possible equilibrium action is 2 playing $N(\beta)$, and similarly if 2 waits.

Q.E.D.

Proof of Proposition 2: Let

$$
E_{H S}^{I A}=E_{H S_{0}}^{I A} \cup E_{H S_{1}}^{I A} \cup E_{H S_{2}}^{I A},
$$

where

$$
E_{H S_{0}}^{I A}=\left\{\left(q_{1}^{1}, q_{1}^{2}\right): q_{1}^{1}=q_{1}^{2}, \text { and } N(\beta) \leq q_{1}^{i} \leq N(\alpha), i=1,2\right\},
$$

and

$$
E_{H S_{i}}^{I A}=\left\{\left(q_{1}^{i}, q_{2}^{j}\right)=\left(L^{i}(\alpha, \beta), t^{j}\left(L^{i}(\alpha, \beta)\right)\right)\right\}, i=1,2 .
$$

Let $\left(a^{1}, a^{2}\right)$ be any point in $E_{H S_{0}}^{I A}$. Since $a^{2}$ is a best reply to $a^{1}$, neither waiting nor any other output choice in the first production period can raise 2's payoff, and similarly for 1 . Thus, any point $\left(a^{1}, a^{2}\right)$ in $E_{H S_{0}}^{I A}$ is an equilibrium. Now consider the situation where firm 1 plays $L^{1}(\alpha, \beta)$ in the first production period and firm 2 waits and then plays $t^{2}\left(L^{1}(\alpha, \beta)\right)$ in the second production period. This is equilibrium since the assumption that $U^{1}(N(\beta), N(\beta))<$ $U^{1}\left(L^{1}(\alpha, \beta), t^{2}\left(L^{1}(\alpha, \beta)\right)\right)$ implies that 1 can not gain by deviating from $L^{1}(\alpha, \beta)$ in the first production period. Similarly, 2 playing $L^{2}(\alpha, \beta)$ in the first production period and 1 playing $t^{1}\left(L^{2}(\alpha, \beta)\right)$ in the second production period is an equilibrium. No other outcome can be a subgame perfect equilibrium. A situation where 1 and 2 play $\left(b^{1}, b^{2}\right)$ in the first production period with $\left(b^{1}, b^{2}\right) \notin E_{H S_{0}}^{I A}$ is not an equilibrium since at least one of the firms is not playing her best reply to the other firm. If 1 waits, the only possible equilibrium action is 2 playing $L^{2}(\alpha, \beta)$, and similarly if 2 waits.

Q.E.D. 